\title{
Research on the Path of Realizing the College Cultivation System of Innovative Talents from the Perspective of Big Data
}

\author{
Zhihua Xu \\ School of Management \\ Yangtze Normal University \\ Chongqing 408100 China
}

\begin{abstract}
With the emergence of new types of information dissemination methods such as blogs and social networks, coupled with the rapid rise of technologies such as cloud computing and the Internet of Things, data is continuing to grow and accumulate at a crazy rate, which has already predicted the arrival of the era of big data. The era of big data is an information age based on data storage, value refinement, intelligent processing and display through massive collection of data resources using modern network channels, and its essence is to collect, analyze and apply big data. Big data-driven reform and development of higher education is gradually attracting the attention of the academic community, and the big data-driven higher education quality monitoring and evaluation, big databased higher education governance and management, and scientific decision-making in teaching have also become the hot issues in big data research of higher education. On the basis of summarizing and analyzing previous research works, this paper expounds the current situation and challenges of innovative talent cultivation in colleges and universities under the background of big data, analyzes the important influence of big data on the college innovative talent cultivation, and proposes the way to realize the college innovative talent cultivation system based on big data. The study results of this paper provide a reference for the further study of the college innovative talent cultivation system under the perspective of big data.
\end{abstract}

Keywords-Innovative talent cultivation; Big data; Higher education

\section{INTRODUCTION}

As a complex and multi-mobile research direction in the Internet era, innovative talent cultivation has undergone tremendous changes compared with the industrial era. The research direction of the industrial era is mainly large, internalized and centralized. The main research is on the standard and group behavior. In the Internet age, the research direction of the organization is miniaturization, externalization and separation. The individual individuals are mainly studying their individuality. Big data is a huge database that extracts very useful data and information to help understand the situation, find problems, and make decisions; this is a new technology and a new way of thinking; no doubt, Big data will affect all aspects of social life, all walks of life, and talent cultivation is no exception. The era of big data refers to the era of information storage, value refinement, intelligent processing and display based on the massive collection of data resources through modern network channels. The essence of the era of big data is the collection, analysis and application of big data. The era of big data is a new era in which social productivity has developed to a certain extent. It has had a huge impact on people's production and lifestyle. Everyone is more or less affected by big data [1].

Due to the fact that the educational process and practice field rely on tradition to reveal the causal relationship between elements, the subject research and professional exploration are unable to arrive when they gradually approach the ultimate goal of innovative talent cultivation. Big data technology that discovers the relationship between various factors in innovative talent in a large number of complex, multi-dimensional and interdisciplinary data may provide a new perspective for the cultivation of innovative talent in universities. Although higher education as a data-intensive area has the characteristics of large data, diverse types and low value density, it still faces many technical problems in real-time data collection, highspeed transmission and processing of big data. For college teacher, having strong data literacy is an inevitable choice for adapting to the needs of innovative talent in the big data era and the requirements for higher education development. However, in the face of the emerging big data technology and the higher education that is entering the critical period of reform, how to realize the comprehensive improvement of teachers' data literacy in the history of big data and higher education integration, and then realize big data and higher education. The deep integration is a major challenge facing the current higher education institutions [2].

On the basis of summarizing and analyzing previous research works, this paper expounds the current situation and challenges of innovative talent cultivation in colleges and universities under the background of big data, analyzes the important influence of big data on the college innovative talent cultivation, and proposes the way to realize the college innovative talent cultivation system based on big data. The study results of this paper provide a reference for the further study of the college innovative talent cultivation system under the perspective of big data. The detailed chapters are organized as follows: Section 2 introduces the current of college innovative talent cultivation under the background of big data; Section 3 expounds the influence of big data on the college 
innovative talent cultivation; Section 4 proposes the realizing path of innovative talent cultivation system based on big data; and Section 5 is conclusion.

\section{CURRENT SITUATION OF COLLEGE INNOVATIVE TALENT CULTIVATION UNDER THE CONTEXT OF BIG DATA}

Big data comes first with changes in computational thinking and cognitive models. Computational thinking belongs to people who use computer science thinking and methods to solve problems, systematic design and understanding of human behavior. With the advent of the era of big data, computational thinking will be one of the most basic ways of thinking, just like mathematics and physical thinking. The cultivation of computational thinking ability will become the professional teaching content of information system, and it is also an important part of basic teaching. In the cognitive process, it will also be transformed from a design based on guessing assumptions to a summary based on facts and experiences. The paradigm of scientific development will also be transformed from computational simulation to data exploration in the past few decades. Theory, practice, and simulation are all unified into this data exploration framework for information processing.

In the future, the demand for talent with big data management and analysis capabilities will grow rapidly. At the same time, some big data-related positions will emerge, such as big data analysts, big data architects, big data application development engineers. Big data analyst is responsible for using data mining algorithms to solve and analyze problems and make data play its value; big data architect is responsible for big data system development, including large-scale unstructured data business model building, big data storage, database construction, optimization of database architecture, solution of database center design, and so on; big data application development engineer is responsible for building big data application platform and developing analysis application, extracting data from different sources, converting and importing data warehouse to meet the needs of enterprises. Big data also brings network thinking, which expands the individual thinking in the computer age, thus creating new requirements for talent cultivation, that is, network thinking ability will become the ordinary skills of future college students.

In the era of big data, with the improvement of cognitive computing ability, people's ability to monitor and analyze data is constantly strengthened. Some factors that are difficult to measure will be quantified. With the development of cuttingedge technology, evaluation indicators will be easier from macro to micro. In terms of evaluation of teachers' teaching activities, based on the traditional evaluation model, the course content, teaching methods, students' sense of acquisition, and teacher student harmony should be more important indicators. At the same time, teachers should also reform the assessment of students' academic performance. In addition to the traditional test paper scores, the evaluation of professional learning ability, leadership ability, cooperation ability and communication ability in the learning team should also become an important assessment content. Source sharing makes it a student's greatest expectation to receive personalized education.
Students will no longer be willing to learn information that can be easily obtained through the Internet in the public classroom, and pay more attention to the more in-depth private cloud information in the professional field. In addition, with the development of computational cognitive ability and the increasing attention to individual students, teachers can gradually make accurate representations of students' personality needs, thus creating conditions for individualized education for students. Small class teaching will become the norm to meet individualization. The precise teaching activities required by the requirements will become the basic teaching requirements, and the significance of individual improvement of business management and leadership skills is more obvious [3].

Data experts are not only full-time personnel dealing with big data, but also leaders in the field of science and technology research and industry innovation in the era of big data, and are responsible for promoting economic development. Therefore, in order to ensure the quality of data experts, it is urgent to develop corresponding qualification standards. Colleges and universities should actively promote the cultivation of big data talent of different levels and types and assist in the establishment of qualification certification systems, such as data analysts, data architects, and data engineers. It defines the skills and knowledge of data experts, and establishes an evaluation system so that the data experts' business execution ability can be properly judged, so that the big data related market can be developed soundly. At the same time, in the school-enterprise cooperation, colleges and universities should actively cooperate with enterprises to implement schoolenterprise cooperation, and promote the enterprise tutor system and cultivate both on the basis of joint education, talent cultivation programs, cooperative development courses, and the construction of a "double-teacher" structure teaching team. Big data requires a combination of professionals who understand both data analysis technology and relevant business knowledge, and who have rich theoretical knowledge and rich practical experience.

\section{INFLUENCE OF BIG DATA ON THE COLLEGE INNOVATIVE TALENTS CULTIVATION}

The great development of the era of big data has brought better development opportunities to related work in higher education institutions. Under the influence of the data age, colleges and universities began to think about traditional management methods and management concepts. They are particularly prominent in the related concepts of talent management. The most direct performance is the concept of talent management, network technology, and service transformation. The data analysis method is a new method for colleges and universities to adapt to the development of the data age, and is also an important measure to improve the competitiveness of higher education institutions. In the data age the relevant methods of using data analysis in higher education institutions have practical value (Fig. 1). Moreover, from the perspective of actual work, the talent cultivation work of colleges and universities already has the relevant characteristics of data. The personnel information of the personnel departments of higher education institutions are in contact with 
the work, the compensation statistics of related companies, and the performance management of each college. The calculation of labor compensation, etc. requires a large amount of data to participate. The collection and storage of a large amount of data will cause great troubles in the later related management work. Especially in higher education institutions, there are many branches, branches of branches, professional branches, branches of departments, etc. In this case, the data generated in different departments and different fields, data collection which department is responsible for the work and the data classification work is an urgent problem.

Since the basis vectors of the linear space of innovation ability are abstract values, it is difficult to observe and measure. To this end, this abstract value needs to be transformed into observation measurement. The ability to accumulate knowledge can be observed from the depth, breadth and time validity of knowledge; knowledge transfer ability can be measured from knowledge transfer ability and transfer cost; knowledge classification and integration management ability can be measured from knowledge classification ability, management ability and deductive reasoning ability; thinking imagination can be observed from imagination and reverse thinking ability; practice the operational ability may be calculated by the quality of the course experimental design and the quality of the graduation design; the psychological control ability can measure the willpower and execution power through measurement. The formulation of the talent cultivation system is mainly based on the productivity and science and technology, economic and social development, and the level of physical and mental development of the educated, and adapts to the needs of economic and social development and the development of students' individuality. The construction of the talent cultivation system is a systematic project involving the integration of teaching content and the optimization of the curriculum system. It is not a simple mechanical accumulation of teaching content [4].

In the process of talent cultivation in the context of big data, all talent needs to be trained to cooperate with each other. How to integrate the needs of all parties is the key to the talent output of colleges and universities to meet the actual needs of society. In the model, the relationship between the position and the ability network is used to reflect the ability of the relevant positions. It helps to determine the target of the reform of the talent cultivation program and the employment of the students. Secondly, use the relationship between the ability and the knowledge network to find out that there is a certain The domain knowledge that should be mastered by these abilities; in addition, through the knowledge and course network, according to the logical structure of knowledge, rationalize the time series relationship between the courses; Finally, use the curriculum and ability network to match the specific cultivation resources of the university, and explain the cultivation ability. Cultivating orientation is the intersection of social needs, student and college needs. Accurate culture positioning is conducive to scientific cultivation objectives and specific cultivation quality standard design, providing clear guidance for professional cultivation program adjustment, teaching content and method improvement, teacher configuration and use, etc., so as to improve the targeted and scientific input of each teaching element.

Big data-driven innovation talent cultivation is a technical issue, and then an education issue. There is no big data technology suitable for higher education. Without the deep integration of higher education and these technologies, big data-driven innovation talent cultivation is destined to be an unspeakable educational ideal, beautiful and powerless. Obviously, it is the first step to make full use of the leverage of big data to train innovative talent in higher education and realize the leap of big data from higher education to big data technology. Although many colleges and universities have strong strengths of research and development in big data technology, they are more practical and closer to application scenarios than Internet companies' research and development, application and promotion advantages in big data technology. The big data technology realizes the deep integration of big data plus higher education, and then promotes the cultivation of innovative talent in higher education is an important path for higher education to break through in the short-term. Of course, colleges and universities collaborate with Internet companies to explore new data-driven innovative talent to cultivate new thinking and new models. It is necessary to be wary of enterprises with obvious profit-seeking characteristics as market entities that may improperly use higher education big data to avoid this data ethics and ethical issues.

\section{PATH OF COLLEGE INNOVATIVE TALENT CUltivation SYSTEM BASED ON BIG DATA}

In the era of big data, the demand for high-quality and innovative talent is increasing. Therefore, in response to the call of the times, major universities are actively pursuing innovative and entrepreneurial courses in schools, so that the professional knowledge of students studying at school can be practically applied. In order to achieve this goal, the teaching curriculum system of major universities needs to make appropriate adjustments and reforms, and arrange teaching tasks according to the characteristics of the times and the specific conditions of students, in order to meet the characteristics of modularity, multi-level and orientation of the curriculum of innovation and entrepreneurship. To cultivate students' innovative and entrepreneurial education concepts in colleges and universities, we must first choose a scientific innovation and entrepreneurship curriculum and formulate a reasonable teaching system. This is a key issue for college students to cultivate innovative entrepreneurship education concepts. The school usually starts from two systems. On the one hand, it is to strengthen the concept of innovation and entrepreneurship in the professional curriculum of students. On the basis of learning the theoretical curriculum in the past, it has added practical courses such as corresponding entrepreneurial practice skills. On the other hand, it is open. The innovative entrepreneurship program allows students to understand and master the theoretical knowledge related to innovation and entrepreneurship in the classroom, and to study some specific examples of innovation and entrepreneurship, so that students can have a more comprehensive understanding of it and allow students to learn from it. Experience has thus expanded the sense of innovation (Fig.1). 


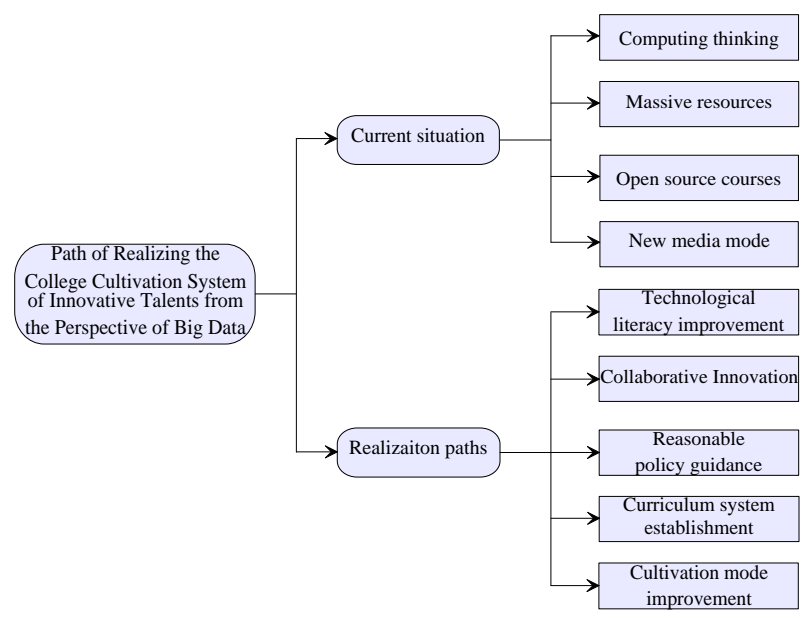

Fig. 1. Current situation and realization paths of college cultivation system of innovative talents from the perspective of big data

Under the background of big data, the cultivation of talent in colleges and universities should gradually transform the existing traditional education methods of imparting knowledge into the individualized teaching methods of thinking ability cultivation, continuously cultivate students' independent learning ability, and integrate the cultivation of scientific thinking ability into the overall classroom teaching process. To change the teaching thinking of the theory and practice in the past, teachers should make full use of their rich experience, and try to run through more practical cases in practical teaching, so that students can be more perceptual and concrete in their understanding of the professional knowledge they have learned. It is no longer the knowledge point of the abstract learning profession. At the same time, when guiding students to use the knowledge they have learned to solve professional problems, they can also set certain cases so that students can understand the problems and solve problems more concretely. In the classroom, students' thinking can be broadened as much as possible, and students' innovative ways of thinking can be cultivated to become more innovative and supportive in the future study and work, and to help the development of software technology.

Big data provides a new opportunity for the development of innovative talent in universities and colleges for the development of innovative talent in universities. The government plays a role in environmental support and macrocontrol in policy formulation and resource integration and at the same time builds a platform for communication and cooperation between universities, research institutes and enterprises. The cooperation between universities, research institutes and enterprises is conducive to the transformation of scientific and technological achievements, and is conducive to the cultivation and development of students' innovation and entrepreneurship activities; students and mass users as the ultimate beneficiaries, but also consumers of technological achievements, promoting higher education The reform and development and the continuous progress of the economy and society. At the same time, when colleges and universities connect with enterprises, they can grasp the needs of enterprises, so as to timely update and adjust the talent cultivation mode, professional settings and talent cultivation programs, so that the talent cultivated by universities can better meet the needs of the market, thus improving the employment rate of college graduates. The college has established scientific and technological achievements transformation center based on a strong scientific research platform. Research institutes such as various research laboratories, experimental centers, engineering technology centers, and scientific and technological achievements transformation centers of the college can also provide early access to scientific research platforms [5].

The analysis data set is centered on the basic researchers, and other researchers are equipped to analyze the data indicators. The basic scientific research personnel, combined with the key indicators of scientific and technological talent in the talent project funding and job title declaration, screens the key indicators of the scientific and technological talent forecasting model, and explores the relationship between various indicators, especially the key links of talent development from hidden indicators. It excavates the relationship between valuable indicators from seemingly unrelated data, and finds potential relationships among various data, so as to achieve targeted cultivation, change concepts and concepts, and realize the organic spontaneous development of talent. The current cultivation not only needs to be controlled from the traditional means of cultivation needs research, cultivation plan development and cultivation effect evaluation, more needs cultivation to form a system, and horizontally strengthens the connection and application of human resource management modules such as job title promotion and performance management. Vertically link the internal development goals, organizational capabilities and personal development needs of the unit, thereby forming a virtuous circle system combining the development of talent and the development of talent.

\section{CONCLUSIONS}

On the basis of summarizing and analyzing previous research works, this paper expounds the current situation and challenges of innovative talent cultivation in colleges and universities under the background of big data, analyzes the important influence of big data on the college innovative talent cultivation, and proposes the way to realize the college 
innovative talent cultivation system based on big data Big data comes first with changes in computational thinking and cognitive models. Computational thinking belongs to people who use computer science thinking and methods to solve problems, systematic design and understanding of human behavior. The data analysis method is a new method for colleges and universities to adapt to the development of the data age, and is also an important measure to improve the competitiveness of higher education institutions. In the process of talent cultivation in the context of big data, all talent needs to be trained to cooperate with each other. To make full use of the leverage of big data to train innovative talent in higher education, it is the first step to realize the leap of big data from higher education to big data technology. Source sharing makes it a student's greatest expectation to receive personalized education. Students will no longer be willing to learn information that can be easily obtained through the Internet in the public classroom, and pay more attention to the more indepth private cloud information in the professional field. Big data provides a new opportunity for the development of innovative talent in universities and colleges for the development of innovative talent in universities. The government plays a role in environmental support and macrocontrol in policy formulation and resource integration and at the same time builds a platform for communication and cooperation between universities, research institutes and enterprises.

\section{ACKNOWLEDGEMENT}

In this paper, the research was sponsored by The 13th FiveYear Plan for Education Science in Chongqing: "Research on the Cultivation System of College Innovative Talents in Chongqing" and Yangtze Normal University Teaching Reform Project: "Research and Practice on the Innovation Ability of Management Talented Person” (No.JG201731)

\section{REFERENCES}

[1] Shao Y.F., Zheng Y., Wang L.M. Exploration on the cultivation mode of compound innovative talents under the perspective of university collaborative innovation-Taking UESTC as an example. Journal of UESTC (Social Sciences Edition), 2017, 19(1):15-19.

[2] Gui J.Y. Research on the cultivation of financial management professionals in universities in the background of big data. Theory and Practice of Education, 2018, 38(30): 41-42.

[3] He K. Research on the construction training system for top financial undergraduates in the era of big data. Research and Practice on Higher Education, 2015, 34(3): 55-61.

[4] Tian S.H. Research on college talent training super network model under the background of big data. Science Technology and Management, 2016 , 18(1): 77-81.

[5] Yang W.R. Study scientific research management innovation of colleges and universities in big data era. Science and Technology Management Research, 2015, (14): 1-4. 